\title{
Preparation of Smart Fluid from Polymer Coated Pumice Particles
}

\author{
Hasim Yilmaz*, Abdullah Çalışkan, Ümmihan T. Yilmaz \\ Chemistry Department, Polatli Science and Letters Faculty, Gazi University, Ankara, Turkey \\ Email: "hasim@gazi.edu.tr
}

Received 12 January 2016; accepted 28 August 2016; published 31 August 2016

Copyright (C) 2016 by authors and Scientific Research Publishing Inc.

This work is licensed under the Creative Commons Attribution International License (CC BY). http://creativecommons.org/licenses/by/4.0/

(c) (i) Open Access

\begin{abstract}
This study reports, electrorheological (ER) responses of pumice and poly(methyl methacrylate)/ pumice, PMMA/pumice, conducting composite dispersions in silicone oil (SO). Primarily three different compounds (K1, K2, K3, 73\%, 48\%, 22\% contain pumice particles) PMMA/pumice composites were prepared and used as ER active materials. Anti-sedimentation stabilities of pumice and composite systems in silicone oil (SO) medium were determined. The application of a suspension of composite particles as an electrorheological ER fluid (20\% particle concentration) was assessed using a rotational electro-rheometer, and the effects of the electric field strength, shear rate, frequency and temperature were examined. ER activity of all the composite suspensions was observed to increase with increasing concentration, electric field strength and decreasing shear rate. The PMMA/pumice composites suspensions show a typical shear thinning non-Newtonian viscoelastic behavior, in which viscosity of the suspension decremented sharply with incrementing shear rate. The ER measurement results showed that the performance of the composite suspensions was enhanced by increasing the electric field strength.
\end{abstract}

\section{Keywords}

Electrorheological Fluids, Polymer Composite, Poly(Methyl Methacrylate), Elastic Modulus

\section{Introduction}

An electrorheological (ER) fluid is described as a smart material, in which the electrorheological properties of a suspension of particles dispersed in an insulating oil, can transmute from a liquid-like state to a solid-like state in the range of milliseconds from the application of an external electric field [1]. Under the electric field strength, the induced dipoles tend to attract neighboring particles and this causes the particles to form fibrillar three-

${ }^{*}$ Corresponding author. 
dimensional network structures, which are aligned along the direction of the electric field and generate additional resistance against fluid motion [2].

Without an external electric field, conducting particles are dispersed haphazard and the ER fluid comports simply as a Newtonian fluid. When an externally applied electric field strengthens, the dispersed particles immediately form chain-like structures and the ER fluid deports as a non-Newtonian fluid [3].

Igneous rocks of volcanic pumice are very thin with translucent bubble-walled glass pyroclastic extent macrovesicle structure. This is an intermediate silicic structure; there is no widely-circumscribing or basalt and felsic composition in others. Pumice is commonly pale in color, ranging from white, cream, blue or grey, to greenbrown or ebony. It composes when volcanic gases ex-solve from viscous magma-nucleate bubbles which cannot yarely decouple from the viscous magma prior to chilling to glass. Pumice widely in the upper components of silicic lava is a prevalent product in the form of explosive blast. Pumice has an average porosity of $90 \%$. Pumice is typically used to make a lightweight insulating concrete or cinder block of low density. Pumice has been utilized as a construction material to the present from the past [4].

PMMA is known as a vigorous and lightweight material. It has a density of $1.17-1.20 \mathrm{~g} / \mathrm{cm}^{3}$, which is less than a moiety that of glass. In integration, the polystyrene has a higher glass and good impact resistance; however, the PMMA impact vigor is still significantly lower than polycarbonate and some engineered polymers. PMMA swells and dissolves in many organic solvents; it also has poor resistance to many other chemicals due to its easily hydrolyzed ester groups [5]. Nevertheless, its environmental stability is superior to most other plastics such as polystyrene and polyethylene, and PMMA has been therefore often the material of choice for outdoor applications. However, environmental stability, such as polystyrene and polyethylene is superior to many other plastics and PMMA therefore for alfresco applications and often a preferred material in many areas [6].

In this study, all these superior features with pumice composite PMMA are intended as a preparation. For this intent, three different compounds (K1, K2, and K3) PMMA/pumice composites were used as ER active materials. In this system, the silicone oil was determined by precipitation resistance. The parameters which affect the ER properties of pumice/SO and PMMA/pumice/SO systems were investigated such as electrical field strength, shear rate, shear stress, elastic properties and temperature [7].

\section{Experimental}

\subsection{Materials}

Pumice mineral "Soylu Mining" companies from (Cappadocia province, Turkey) and for all other chemicals provided by Aldrich products and used as received. The monomer, methyl methacrylate (MMA) was used after vacuum distillation. The initiator of ammonium per sulfate (APS) was recrystallized in ethanol prior to use.

\subsection{Preparation of PMMA/Pumice Composite}

PMMA was free radical polymerized in the presence of pumice using APS (ammonium persulfate) as radical initiator taking the monomer to initiator mole ratio as $1000: 1$ in methanol (at $70^{\circ} \mathrm{C}$ ) [8]. The reaction system was kept at room temperature under $\mathrm{N}_{2}$ (g) for $4 \mathrm{~h}$ commixing. During the mixing, the addition of pumice adsorbed PMMA surface and was added at three different rates (Scheme 1). Prepared composites were dried under vacuum for 24 hours. Three PMMA/pumice composites, containing sundry percentages of PMMA were prepared by changing the pumice to monomer ratios, and they were coded as follows: 27\% PMMA/73\% pumice (K1), 52\% PMMA/48\% pumice (K2), 78\% PMMA/22\% pumice (K3). And then composites milled with ball mill. Determining particle size and electrical characteristics are given in Table 1.

\subsection{Scanning Electron Microscopy}

The SEM micrographs of PMMA/pumice composites (Figure 1) demonstrates a big granular structure whereas, the SEM micrograph of PMMA/pumice composites demonstrates a sponge like and porous structure. The different surface morphologies of PMMA and PMMA/pumice composites influence their conductivities.

\subsection{Preparation of Dispersions}

Dispersions of pumice and PMMA/pumice composite were prepared at a volume fraction of $20 \%$ by dispersing 

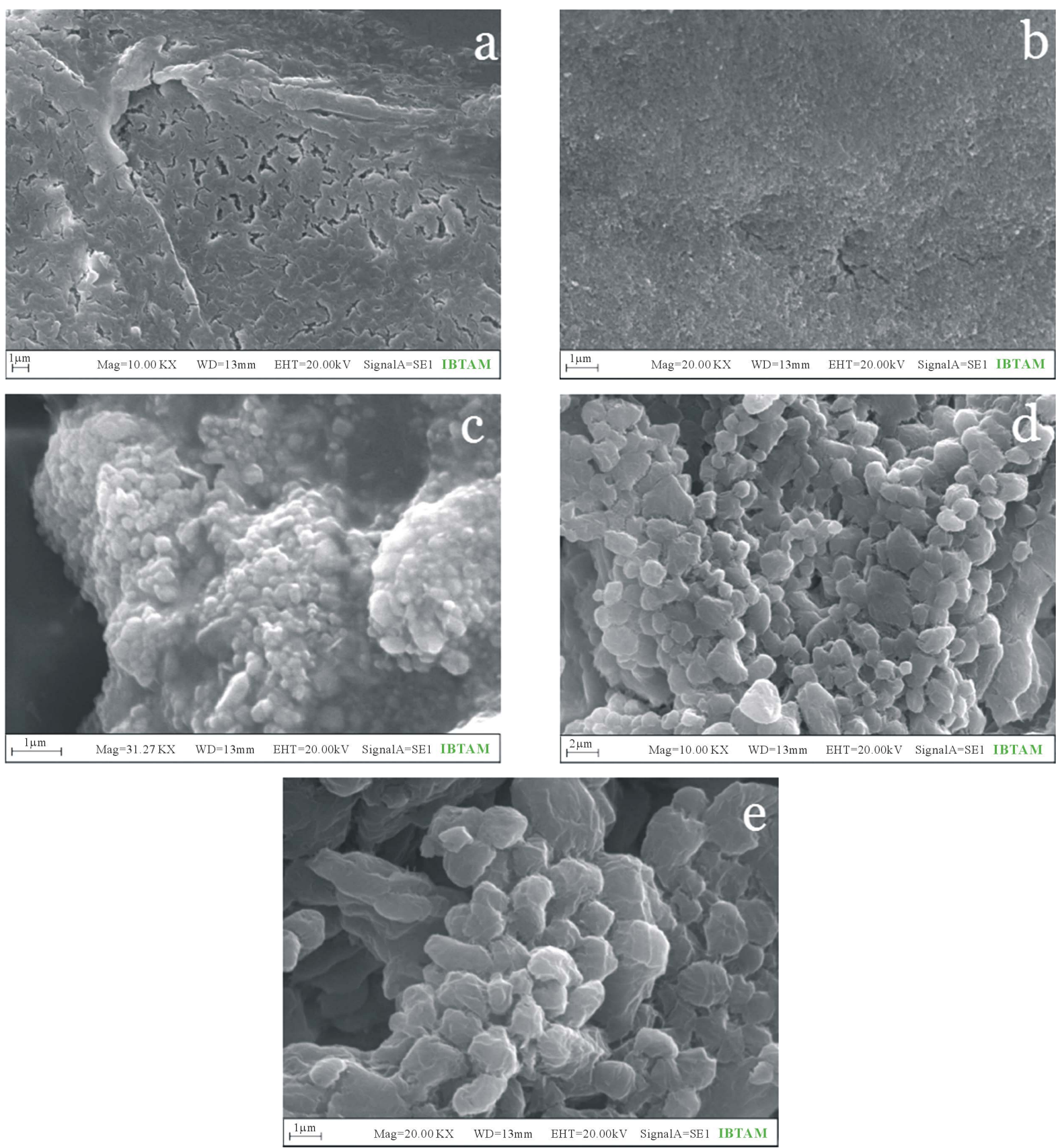

Figure 1. SEM figures. (a) PMMA; (b) Pumice; (c) K1; (d) K2; (e) K3.

Table 1. Particle diameter, conductivity and dielectric parameters of samples.

\begin{tabular}{cccc}
\hline Sample & $\left(d_{0.5}\right)(\mathrm{nm})$ & $\sigma\left(\mathrm{S} \cdot \mathrm{m}^{-1}\right)$ & $c=\kappa \varepsilon_{0} \frac{A}{d}$ \\
\hline K1 (27\% PMMA/73\% pumice) & 1489 & $2.76 \times 10^{-4}$ & 1.24 \\
K2 (52\% PMMA/48\% pumice) & 1105 & $5.17 \times 10^{-4}$ & 1.48 \\
K3 (78\% PMMA/22\% pumice) & 894 & $4.26 \times 10^{-3}$ & 1.55 \\
PMMA & 756 & $4.2 \times 10^{-2}$ & 1.42 \\
pumice & 634 & - & - \\
\hline
\end{tabular}




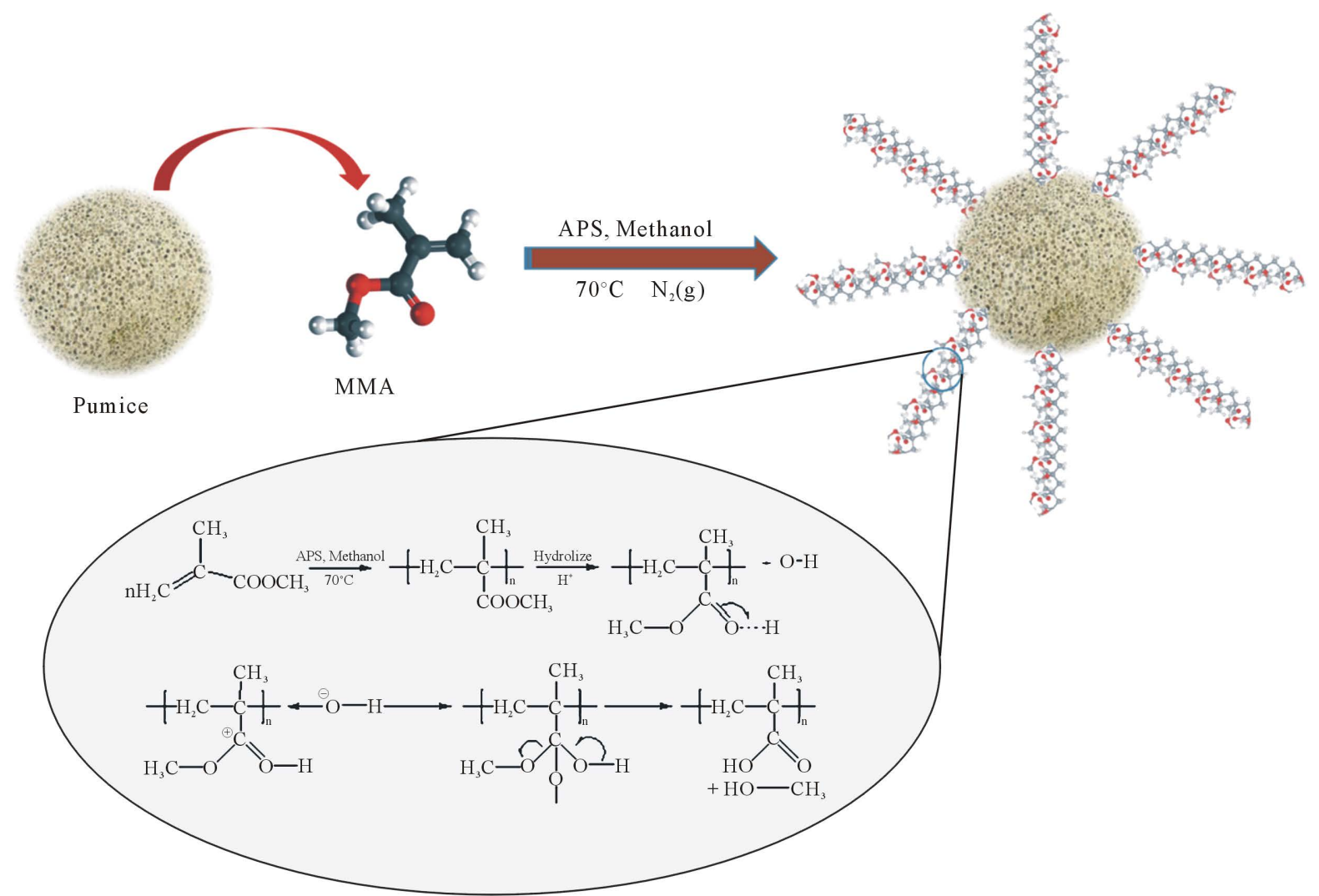

Scheme 1. Procedure of poly(methyl methacrylate)/pumice composites.

definite amount of solid particles in Silicone oil, SO $\left(\rho=0.965 \mathrm{~g} \cdot \mathrm{cm}^{-3}, \eta=1.0 \mathrm{~Pa} \mathrm{~s}, \varepsilon=2.61\right.$, Aldrich, Germany), which were both vacuum dried before mixing in an oven for $24 \mathrm{~h}\left(50^{\circ} \mathrm{C}\right.$ constant temperature) to remove any moisture present. All the prepared dispersions were allowed to equilibrate overnight before measurements.

\subsection{Sedimentation Stability Measurements}

Sedimentation stabilities against gravitational forces of the pumice/SO and PMMA/pumice/SO dispersions were determined at $\mathrm{T}=25^{\circ} \mathrm{C}$. Glass tube containing the above dispersion was immersed in a constant temperature water bath and the formation of the first precipitate was recorded as a colloidal stability. Pure views during the affluent phase for particulate and in terms of a relatively clear phase separation between an oil rich phase heights were recorded as a function of time using digital calipers. Sedimentation rate was defined as the height of the affluent phase divided particles to the total height of the dispersion.

\subsection{Electrorheological Measurements}

ER properties of the dispersions were determined with a Thermo Scientific HAAKE RheoStress 600 Electrorheometer (Karlsruhe, Germany). The gap between the parallel plates was $1.000 \mathrm{~mm}$ and the diameters of the upper and lower plates were $35 \mathrm{~mm}$ (PP35 ER rotor). Potential used in these experiments was supplied by a 0.0 $12.5 \mathrm{kV}$ (with $0.5 \mathrm{kV}$ increments) dc electric field generator (Fug Electronics, HCL 14, Germany), effective resistivity generated during the experiments.

\section{Results and Discussion}

\subsection{Anti-Sedimentation Stabilities of the Dispersions}

The anti-sedimentation stability of ER materials is one of the main gauge because the ER fluids are supposed to be homogeneously dispersed before applying external electric field strength. The effects of dispersed particles 
on the anti-sedimentation ratios of the materials used in this study were examined. For the particle volume fraction of $25 \%$, anti-sedimentation ratios at the end of 40 days were determined as $92 \%$ for PMMA/pumice/SO systems (Figure 2). It was observed that PMMA/pumice/SO dispersion system was extremely stable against gravitational sedimentation than other particle concentrations. It was observed that the PMMA/pumice/SO dispersion system had a higher anti-sedimentation ratio than pumice/SO, although the particle size of PMMA/pumice was bigger than pumice. On the other hand, the density of PMMA/pumice was lower than pumice and more proximate to the density of SO. Furthermore, in composite structure PMMA chains form steric obstruction that holds the particles in suspended positions against agglomeration.

\subsection{Electrorheological Studies}

\subsubsection{Effect of Particle Concentration on ER Activity}

The change in electric field viscosity $\left(\eta_{\mathrm{E}}\right)$ with a suspension particle concentration at constant conditions was shown in Figure 3. There are two main factors which relate the particle concentration and $\eta_{\mathrm{E}}$. The higher particle concentration results in a denser particle structure organized by the influence of $\mathrm{E}$, resulting with a higher resistance against the flow. Additionally, as a result of polarization forces acting between the particles of the suspensions, $\eta_{\mathrm{E}}$ (or ER activity) increases with incrementing particle concentration in the suspensions. Suspension concentration exerts the principal effect on the ER activity. When a particle concentration increases, electric field-induced viscosity of the suspension increases. This may be attributed to the polarizing forces acting between particles [9]. In the absence of an electric field strength, the particles are haphazard dispersed in suspension. At high electric fields, the particles form well-developed strings spanning the gap between the electrodes, as a result of interfacial polarization due to migration of charge carriers in the composite particles. Increase in electric field strength induces a higher dipole moment, which causes the particle chains to coalesce and form thicker chains. Likewise, higher particle concentration results in a denser fibrillar structure [10]. The magnitude of the force between two particles aligned with the electric field strength and with a center-center separation of $d$ is $f_{d}=\frac{6 p^{2}}{4 \pi \varepsilon_{0} K_{f} d^{4}}$ [11]. An incremented suspension concentration will decrement the distance between the particles, which will result in an incremented polarization force. In our study, $\eta_{\mathrm{E}}$ of suspensions increased continuously with increasing particle concentration and this increment was maximum at $c=30 \%$ particle concentration in the following order: K3 (350.8 Pa s) > K2 (312.4 Pa s) > K1 (250.35 Pa s) > pumice (165.30 Pa s). Similar behavior was reported for the study of $\mathrm{CaCO}_{3} / \mathrm{SO}$ suspensions [12].

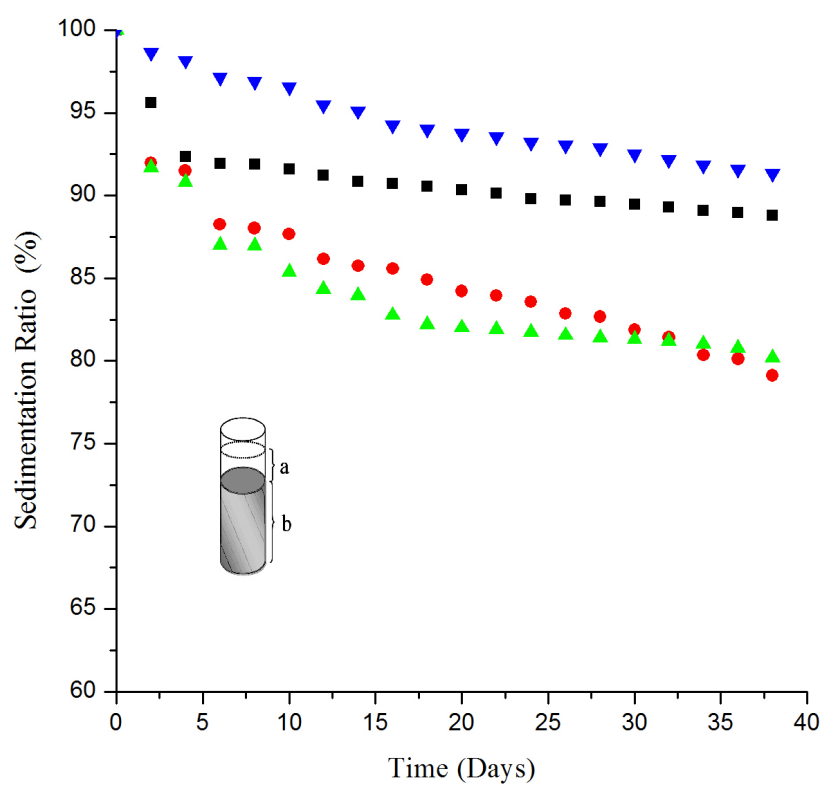

Figure 2. Sedimentation ratio as a function of time for suspensions. $\mathrm{T}=25^{\circ} \mathrm{C}, \mathrm{c}=25 \%(\mathrm{~m} / \mathrm{m})$. 


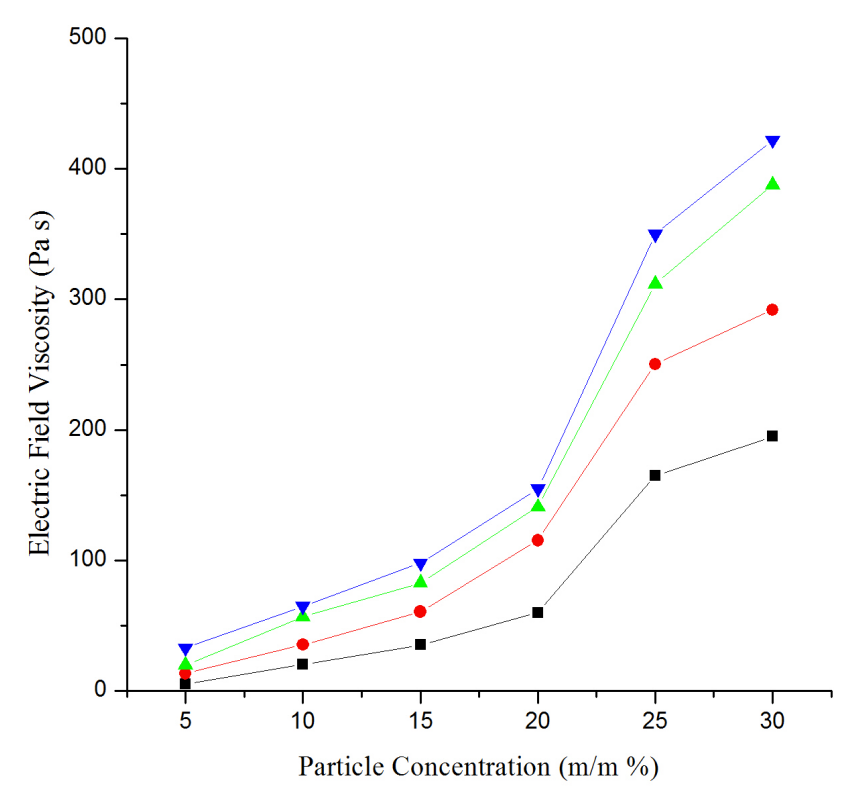

Figure 3. Change in electric field viscosity with particle concentration. $\mathrm{E}=3.5 \mathrm{kV} / \mathrm{mm}, \quad \dot{\gamma}=0.1 \mathrm{~s}^{-1}, \mathrm{~T}=25^{\circ} \mathrm{C}$.

\subsubsection{Effect of Shear Rate on Shear Stress and Viscosity}

The effects of shear rate $\dot{\gamma}$ on shear stress $(\tau)$ and viscosity $(\eta)$ for K3/SO and pumice/SO systems were shown in Figure 4. From Figure 4, it is clear that the apparent shear viscosity attains its largest increases in low shear rate values because, at those values, the stronger electrostatic forces make the particle chains stiffer when standing against the hydrodynamic forces [13]. The viscosities of the systems were observed to decrement exponentially at lower shear rate regions with typical curves of shear thinning non-Newtonian viscoelastic demeanors. Non-Newtonian shear stress increments were observed with incrementing shear rate for all the materials examined. It was concluded that, the interactions between the surfactant molecules and the dispersed composite particles caused the reduction of surface tension of the dispersion system; and additionally the surfactant molecules promoted the colloidal stability of the dispersed particles [14] [15]. At the high shear rate region, the shear stress of all flow curves converges to the same value despite the difference in the applied electric field strength. Thus the applied electric field affects only the low shear rate behavior and the yield stress value [16].

\subsubsection{Effect of Electric Field Strength on Shear Stress and Viscosity}

The pumice and composite nanoparticles dispersed in SO were distributed randomly without applying E (Figure 5). When an electric field was applied, the particles became polarized and inclined to magnetize each other, and consequently the fibril-like structures aligned to the direction of electric field were composed, which provide supplemental resistance against the flow. For composite/SO systems, this occurs under low electric field values and the formation of fibril-like structures could be weak. The composite/SO system showed slight changes in viscosity with increasing electric field. In the presence of an electric field strength, structure of composite/SO dispersion was eradicated by electrostatic forces acting on polarized particles, reorganizing them into fibrillar chains parallel to the electric field, whose resistance against the flow was lower than that of the structure of dispersion with the absence of an electric field.

Shear stress is one of the critical design parameters in ER phenomenon and has attracted considerable attention both theoretically and experimentally [17]. Figure 5 shows the dependence of shear stress on the electric field strength for the four samples studied. Electric field induced shear stress values were observed to increase with increasing pumice content of the composites and changed in the order: K3 $>$ K2 $>$ K1 > pumice. When pumice and composites/SO suspension was subjected to $\mathrm{E}>1.0 \mathrm{kV} / \mathrm{mm}$ an electrical breakdown was occurring and no further data collected.

Additionally Figure 5 shows the change in the electric field viscosity with electric field strength in constant conditions $\left(\dot{\gamma}=0.1 \mathrm{~s}^{-1}, \mathrm{c}=25 \%, \mathrm{~T}=25^{\circ} \mathrm{C}\right)$. Electric field viscosity $\left(\eta_{\mathrm{E} \neq 0}\right)$ increases with increasing electric 

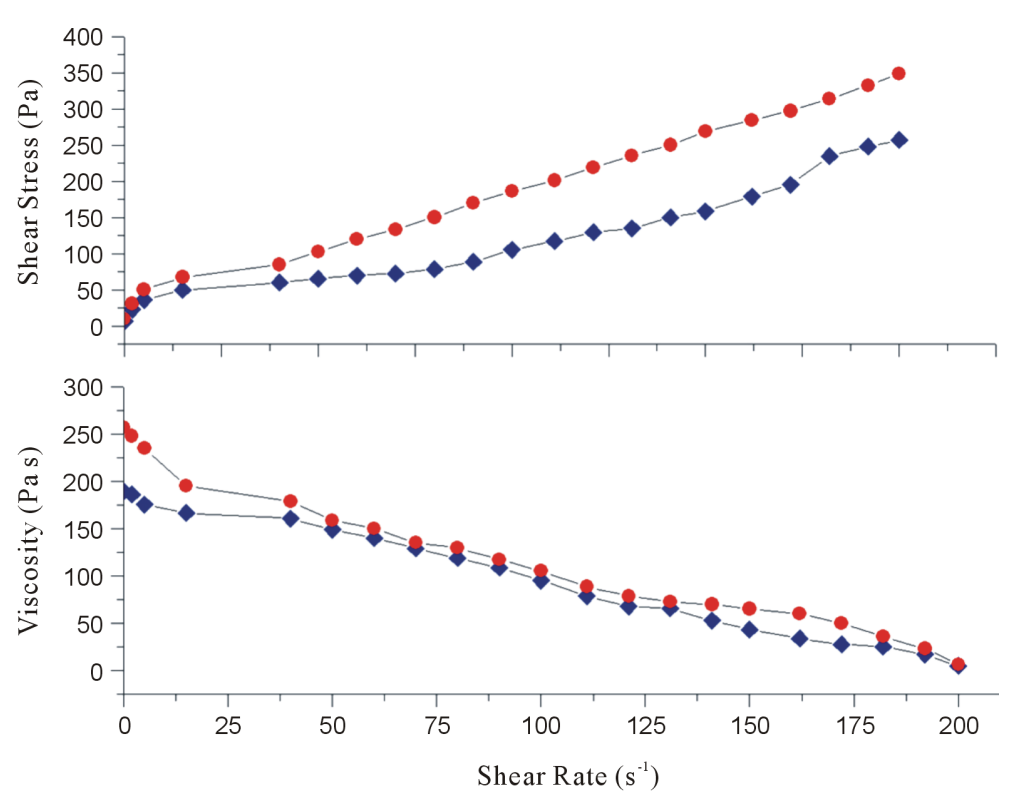

Figure 4. The effect of shear rate on shear stress and viscosity of suspensions. $\mathrm{E}=3.5 \mathrm{kV} / \mathrm{mm}, \mathrm{T}=25^{\circ} \mathrm{C}, \mathrm{c}=25 \%$.

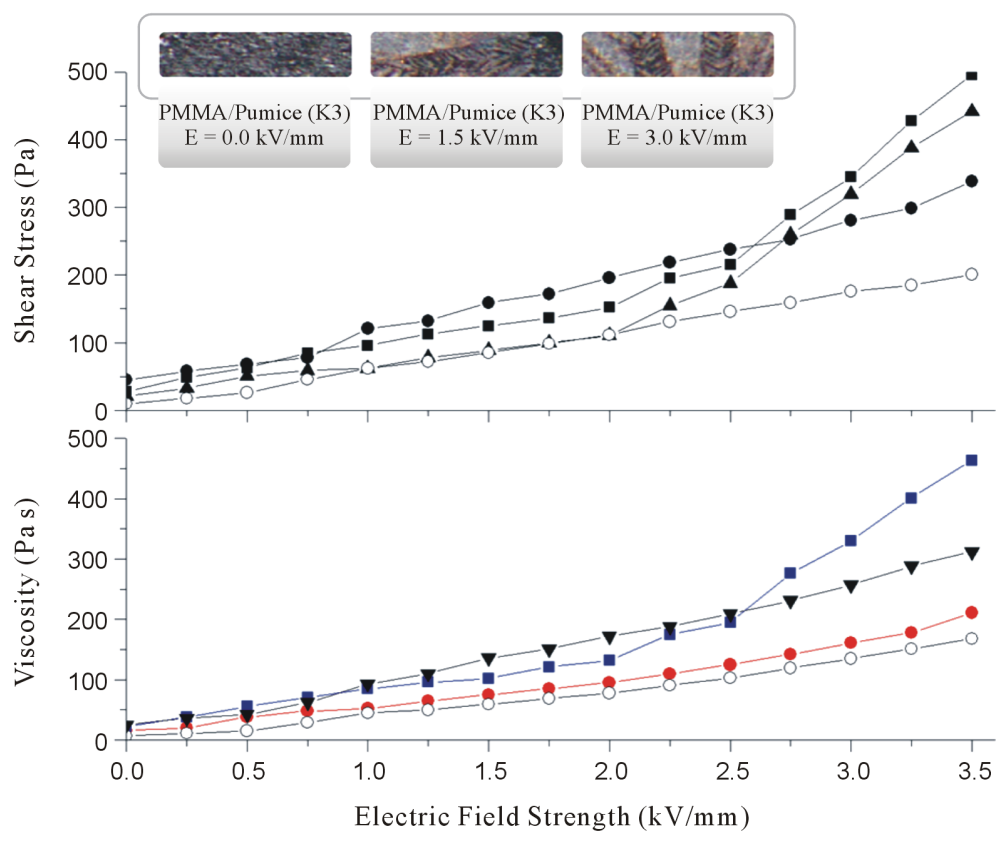

Figure 5. Change in shear stress and viscosity with electric field strength. $\varphi=$ $25 \%, \dot{\gamma}=0.1 \mathrm{~s}^{-1}, \mathrm{~T}=25^{\circ} \mathrm{C}$.

field strength for all the suspensions studied. Under applied electric field strength, the magnitude of the polarization forces between particles increases, and in turn, the particles rapidly aggregate into the chain formation perpendicular to the lower and upper plates, hence resulting in the improvement of the electric field viscosity. During the absence of an electric field strength, the shear stress increases almost linearly with the increasing shear rate. However, in the presence of an applied electric field strength, the shear stress increases abruptly and shows a yield behavior of a typical Bingham fluid, and the apparent shear viscosity exhibits a strong shear thinning behavior [12]. The maximum electric field viscosity was observed as 468 Pas for K3, which contains the highest amount of PMMA. Similar trend was reported by Lu and Zhao [18] for polyaniline/montmorillonite composites. 


\subsubsection{The Effect of Temperature on Shear Stress}

The temperature effect of ER fluid is one of the important parameters to evaluate ER effect [19]. Generally, the temperature has two effects on ER fluids: one is the effect on the polarization intensity of particle and another is Brownian motion. The increase in the temperature resulted with a decrease in polarization activation energy, but with an increase in the polarization ability of the ER particle. Moreover, thermal kinetics and colloidal stability are influenced by change of temperature. The ultimate ER demeanor depends on the balance procured among these factors [20] [21].

To investigate the behavior of materials at elevated temperatures, temperature sweeps were carried out between $25^{\circ} \mathrm{C}$ and $125^{\circ} \mathrm{C}$ for all the suspensions studied (Figure 6). The shear stresses of all the samples, except nanoparticles/SO system, were recorded to decrease with increasing temperature. The overall shear stress losses $\left(\Delta \tau=\tau_{25^{\circ} \mathrm{C}}-\tau_{125^{\circ} \mathrm{C}}\right)$ were in the order of: $\Delta \tau_{\mathrm{K} 3}(43 \mathrm{~Pa})>\Delta \tau_{\mathrm{K} 2}(66 \mathrm{~Pa})>\Delta \tau_{\mathrm{K} 1}$ (74 Pa) and shear stress increment for pumice particle suspensions was calculated to be $33 \mathrm{~Pa}$. With increasing temperature, the thermal motions of the dispersed particles were enhanced; as a result, the mobility of the particles raised and formation of stripes along the direction of the electric field got relatively difficult. pumice/SO system showed slight increment with raising temperature which was believed to cause by its including water and $\mathrm{CO}_{2}$.

\subsubsection{Effect of Frequency on Storage Modulus and Loss Modulus}

It is well known that the relationship between storage modulus ( $\left.G^{\prime}\right)$ and loss modulus ( $G "$ ) indicates whether the material is solid-like $\left(G^{\prime}>G^{\prime \prime}\right)$, gel-like $\left(G^{\prime} \approx G^{\prime \prime}\right)$ or liquid-like $\left(G^{\prime \prime}>G^{\prime}\right)$ in the whole frequency range measured [22].

Viscoelastic properties of K3 composite based ER fluids were measured by an electrorheometer. Figure 7 represents the results from the frequency sweep test. Storage modulus $\left(G^{\prime}\right)$ and loss modulus $\left(G^{\prime \prime}\right)$ under $E=3.5$ $\mathrm{kV} / \mathrm{mm}$ were plotted as a function of frequency in the range from 0.1 to $100 \mathrm{~Hz}$. Therefore, the solid-like property of ER fluid also can be confirmed. Stress sweep was first carried out to determine the proper stress values to ensure collecting data in the linear viscoelastic regime for the samples. G' values of K3/SO were closer to G" values at moderate frequency values and also increased notably with increasing frequency. At lower frequencies the viscous deportment reflected by G" was ascendant, whereas, at the higher frequencies the elastic demeanor reflected by G' was outweighing [23]. This suggests that the fibrillar structure between the electrodes could not occur at lower frequencies. This was because network formation proceeds rapidly and compensates the network break-up under these conditions [24]. Dynamic frequency sweeps at strains well within the linear viscoelastic regime of each composites were performed in a range of frequencies covering 5 decades $(0.01-100 \mathrm{~Hz})$.

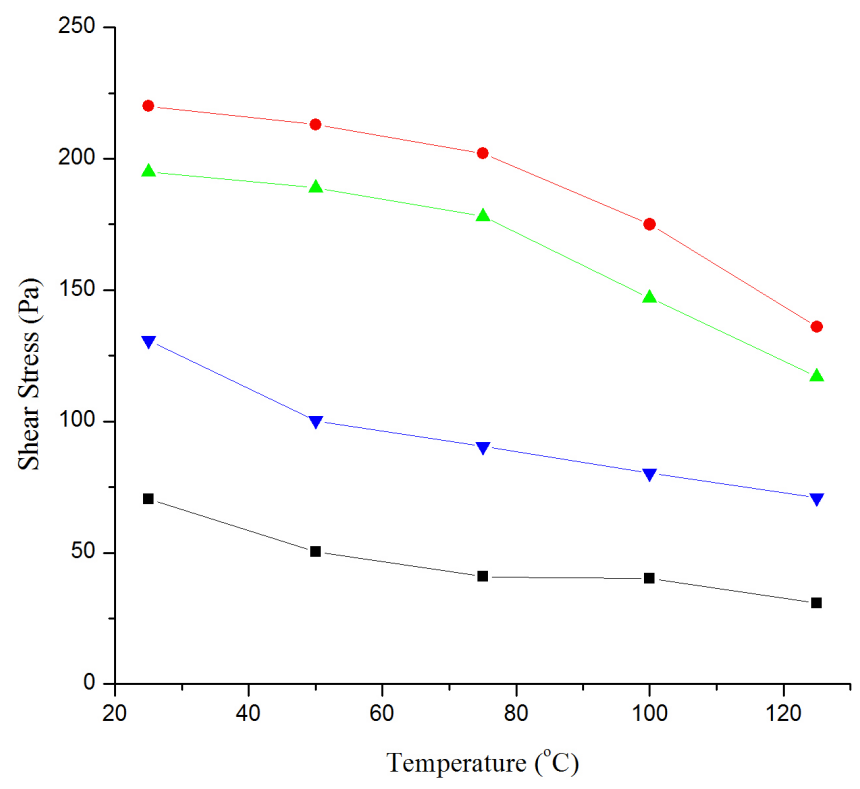

Figure 6. The effect of the temperature on the shear stress. $\dot{\gamma}=$ $0.1 \mathrm{~s}^{-1}, \phi=25 \%, \mathrm{E}=3.5 \mathrm{kV} / \mathrm{mm}$. 


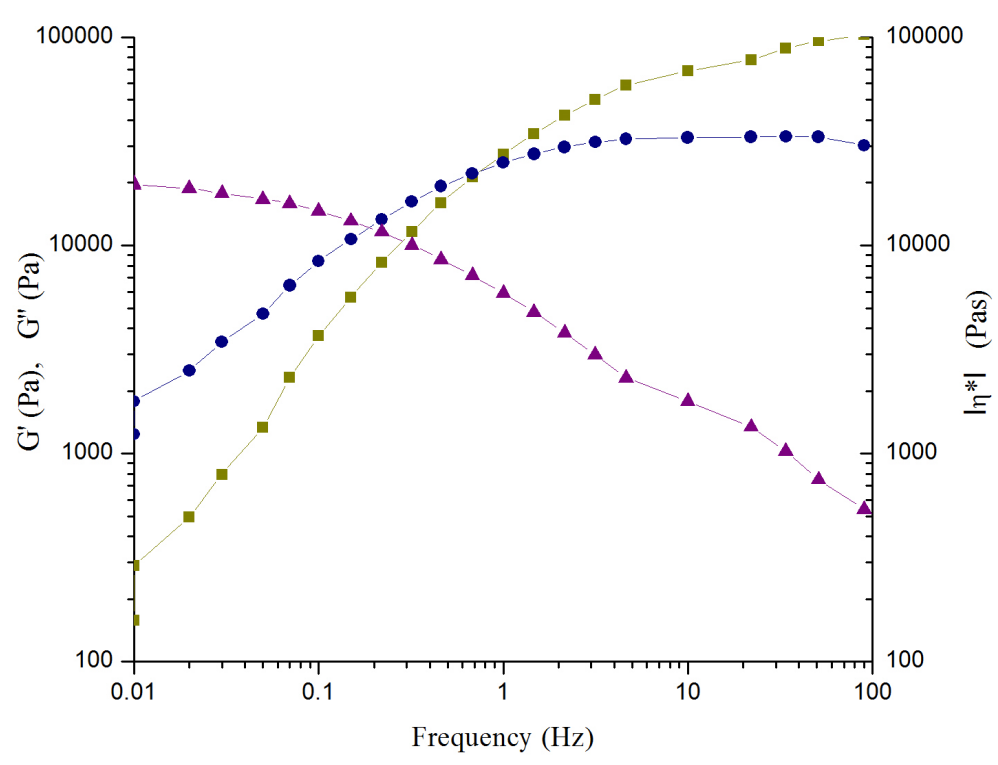

Figure 7. Storage modulus G', loss modulus G" and complex viscosity $\eta^{*}$ in dynamic frequency sweep for K3. $\phi=25 \%$.

The results shown in Figure 7 exhibit the storage modulus G', loss modulus G" and intricate viscosity $\eta *$ for K3. For K3, G', G" and $\eta *$ became too diminutive and scattered for precise quantification at lower frequencies. This was due to the low viscosity of the melt at $25^{\circ} \mathrm{C}$, which led to torque values beyond the constraints of the transducer in the low frequency region. In the middle frequency region, both showed plateaus of proximately constant viscosity. Kindred increment in G' was reported for goethite/SO suspension system at both lower volume fractions and electric field strengths [25].

\section{Conclusion}

Novel ER fluids with poly(methyl methacrylate)/pumice composite structures dispersed in silicone oil have been investigated under both steady and dynamic shear with a rotational rheometer. Sedimentation stabilities of suspensions were increased with increasing pumice content and decreasing dispersed particle concentration of composites. ER activity of all the composite suspensions was observed to increase with increasing electric field strength, dispersed particle concentration and decreasing shear rate. All the suspensions were observed in shown Newtonian flow behavior in the absence electric field, and Bingham plastic flow behavior in the presence of an externally applied electric field. The fluids show typical ER properties in the presence of an electric field strength applied perpendicularly to the flow field. Viscosities of all suspensions were sharply decreased with increasing shear rate, thus showing a shear thinning non-Newtonian flow. Shear modulus of samples was slightly increased with external frequency. Thus, the current study will help to further explore the difference in the ER behavior of spherical particle-based fluids and to explore as-prepared PMMA/pumice composite structures as promising candidates for high-performance smart ER materials.

\section{References}

[1] Jiang, J., Tian, Y. and Meng, Y. (2011) Structure Parameter of Electrorheological Fluids in Shear Flow. Langmuir, 27, 5814-5823. http://dx.doi.org/10.1021/la2002018

[2] Lee, H.J., Byung, D.C., Yang, S.M. and Park, O.O. (1998) Surfactant Effect on the Stability and Electrorheological Properties of Polyaniline Particle Suspension. Journal of Colloid and Interface Science, 206, 424-438. http://dx.doi.org/10.1006/jcis.1998.5661

[3] Kim, H.Y. and Choi, H.J. (2014) RSC Advances, 4, 28511-28518.

[4] Venezia, A.M., Floriano, M.A., Deganello, G. and Rossi, A. (1992) The Structure of pumice: An XPS and ${ }^{27}$ Al MAS NMR Study. Surface and Interface Analysis, 18, 532-538. http://dx.doi.org/10.1002/sia.740180713

[5] Ezrin, M. (1996) Plastics Failure Guide: Cause and Prevention. Hanser Verlag, 168. 
[6] Schwarcz, J. (2012) The Right Chemistry: 108 Enlightening, Nutritious, Health-Conscious and Occasionally Bizarre Inquiries into the Science of Daily Life. Doubleday, Canada, 226.

[7] Ji, L., Zhang, J. and Macromol, J. (2009) Journal of Macromolecular Science, Part A. Pure and Applied Chemistry, 46, 688-693.

[8] Fujii, S., Matsuzawa, S. and Nakamura, Y. (2010) Chemical Communications, 46, 7217-7219.

[9] Wu, S. and Shen, J. (1996) Journal of Applied Polymer Science, 60, 2159-2164.

[10] Chotpattananont, D., Sirivat, A. and Jamieson, A.M. (2004) Electrorheological Properties of Perchloric Acid-Doped Polythiophene Suspensions. Colloid and Polymer Science, 282, 357-365. http://dx.doi.org/10.1007/s00396-003-0945-7

[11] Davis, L.C. (1992) Polarization Forces and Conductivity Effects in Electrorheological Fluids. Journal of Applied Physics, 72, 1334-1340. http://dx.doi.org/10.1063/1.351743

[12] Yilmaz, H., Unal, H.I. and Yavuz, M. (2005) Colloid Journal, 67, 236-241.

[13] Goswami, S., Brehm, T. and Filonovich, S. (2014) MT Cidade. Smart Materials and Structures, 23, Article ID: 105012, $10 \mathrm{p}$.

[14] Hao, T. (2005) Chapter 9-Mechanisms of the Electrorheological Effect. Studies in Interface Science, 22, 475-517. http://dx.doi.org/10.1016/S1383-7303(05)80024-9

[15] Ramos-Tejada, M.M., Arroyo, F.J. and Delgado, A.V. (2010) Negative Electrorheological Behavior in Suspensions of Inorganic Particles. Langmuir, 26, 16833-16840. http://dx.doi.org/10.1021/la1029036

[16] Aua, P., Foo, B., Leong, Y., Zhang, W. and Choi, H.J. (2015) Rheological Analysis of Graphene Oxide Coated Anisotropic PMMA Microsphere Based Electrorheological Fluid from Couette Flow Geometry. Journal of Industrial and Engineering Chemistry, 21, 172-177. http://dx.doi.org/10.1016/j.jiec.2014.07.029

[17] Parthasaraty, M. and Klingenberg, D.J. (1996) Electrorheology: Mechanisms and Models. Materials Science and Engineering: R: Reports, R17, 57-103. http://dx.doi.org/10.1016/0927-796X(96)00191-X

[18] Lu, J. and Zhao, X. (2004) A New Approach of Enhancing the Shear Stress of Electrorheological Fluids of Montmorillonite Nanocomposite by Emulsion İntercalation of Poly- $N$-Methaniline. Journal of Colloid and Interface Science, 273, 651-657. http://dx.doi.org/10.1016/j.jcis.2004.02.066

[19] Liu, B. and Shaw, M.T. (2001) Electrorheology of Filled Silicone Elastomers. Journal of Rheology, 45, 641-657. http://dx.doi.org/10.1122/1.1366716

[20] Yin, J., Xia, X., Xiang, L. and Zhao, X. (2011) Temperature Effect of Electrorheological Fluids Based on Polyaniline Derived Carbonaceous Nanotubes. Smart Materials and Structures, 20, 015002.

[21] Ghasem, N.M. and Al-Marzouqi, M.H. (2011) Effects of Shear Rate, Temperature, and Polymer Composition on the Shear Stress of Polyethersulfone/1-Methyl-2-pyrrolidone Cast Solutions. Journal of Chemical \& Engineering Data, 56, 4444-4448. http://dx.doi.org/10.1021/je2002978

[22] Zou, J., Su, L., You, F., Chen, G. and Guo, S. (2011) Dynamic Rheological Behavior and Microcrystalline Structure of Dioctyl Phthalate Plasticized Poly(Vinyl Chloride). Journal of Applied Polymer Science, 121, 1725-1733. http://dx.doi.org/10.1002/app.33765

[23] Unal, H.I., Cetin, B. and Erol, O. (2013) Electrorheological Response of Polyindene/Colemanite Conducting Composite. Journal of Physics: Conference Series, 412, 012005. http://dx.doi.org/10.1088/1742-6596/412/1/012005

[24] Martins, J.N., Kersch, M., Altstädt, V. and Oliveira, R.V.B. (2013) Poly(Vinylidene Fluoride)/Polyaniline/Carbon Nanotubes Nanocomposites: Influence of Preparation Method and Oscillatory Shear on Morphology and Electrical Conductivity. Polymer Testing, 32, 1511-1521. http://dx.doi.org/10.1016/j.polymertesting.2013.10.001

[25] Ramos-Tejada, M.M., Espin, M.J., Perea, R. and Delgado, A.V. (2009) Electrorheology of Suspensions of Elongated Goethite Particles. Journal of Non-Newtonian Fluid Mechanics, 159, 34-40. 


\section{Submit or recommend next manuscript to SCIRP and we will provide best service for you:}

Accepting pre-submission inquiries through Email, Facebook, LinkedIn, Twitter, etc.

A wide selection of journals (inclusive of 9 subjects, more than 200 journals)

Providing 24-hour high-quality service

User-friendly online submission system

Fair and swift peer-review system

Efficient typesetting and proofreading procedure

Display of the result of downloads and visits, as well as the number of cited articles

Maximum dissemination of your research work

Submit your manuscript at: http://papersubmission.scirp.org/ 